Journal of Psychiatric Intensive Care
Journal of Psychiatric Intensive Care

Vol.1 No.2:61-63

doi: $10.1017 / \mathrm{S} 174264640600001 \mathrm{X}$

(c) NAPICU 2006

\title{
Editorial
}

\section{Informal patients in secure wards: restriction of movement or deprivation of liberty?}

\author{
J Laidlaw, D Buckle \\ Montpellier Low Secure Unit, Gloucester, GL1 3WL, England
}

Those requiring inpatient psychiatric care should be managed in the lowest level of security necessary in a ward close to their home area. The presence of informal (voluntary) patients on secure wards appears incompatible with this principle. Can such situations be justified?

There have been situations of informal patients residing on our low secure ward. On occasion we have also admitted detained patients from open conditions when, arguably, they do not require the physical security but would benefit from therapeutic treatment options unavailable on the open ward.

Our argument is that security in the form of a secure ward's locked door, whilst always leading to some restriction of movement, is not always synonymous with deprivation of liberty. Some patients on secure wards have more access to the community through leave than other patients in open conditions who are restricted to the ward. Thus a patient who resides on a secure ward does not necessarily have less liberty than one on an open ward.

Other factors associated with secure wards can promote greater freedom and autonomy for some patients. Staff to patient ratios tend to be higher on secure wards as compared to open wards. This can facilitate the taking of escorted leave and access to therapeutic activities run by the staff.

Correspondence to: Dr. J. Laidlaw, Montpellier Unit, Wotton Lawn Hospital, Gloucester, GL1 3WL.
Patients admitted to our secure ward, after a period of successful treatment, are often assessed as no longer requiring the physical security inherent in a low secure environment. However it is also often felt that a move to open conditions at that stage is premature as the associated loss of relational security (through the loss of contact with ward staff who have built up personal knowledge and therapeutic relationships with the patient) would lead to unacceptable issues of risk.

We have never admitted an informal patient to the ward but following improvements in their mental health and associated reductions in risk some patients no longer require formal detention and are regraded to informal status. This is because the law in England and Wales stipulates that people detained under the Mental Health Act 1983 should be discharged from section as soon as it is clear that the powers of detention are no longer justified.

Nonetheless, in many cases they are willing to remain on secure wards as informal patients to complete a rehabilitation programme or finalise a discharge plan. Inevitably, in such circumstances, their movement is restricted because, at the very least, they have to ask someone to unlock the door to go out but this does not automatically equate to deprivation of liberty and, thereby, a breach of Article 5 of The Human Rights Act 1998. Unfortunately, there is no neat definition of 'deprivation of liberty' and, currently, there is a paucity of practical guidance with respect to what constitutes deprivation of liberty or restriction of movement in a secure ward. However, informal 
patients would be expected to have much longer periods of unrestricted leave and greater flexibility with regard to the places they are allowed to visit.

The ethical and legal issues associated with informal patients who are deprived of their liberty have been the subject of much discussion in the UK as the 'Bournewood' case proceeded through the courts to the European Court of Human Rights HL v. UK (2005). Indeed, the definition of an informal patient has been central to this case (Puri et al., 2005). The definition of capacity has also recently been legally clarified, in the Mental Capacity Bill, as the ability to understand the information relevant to a decision, to retain that information, to use or weigh that information as part of the process of making the decision and to communicate the decision (whether by talking, using sign language or any other means).

The European Court judgement means that it is unlawful for the National Health Service (NHS) or local authority (without prior authorisation of the High Court) to provide care or treatment for an informal incapacitated patient in a way that amounts to deprivation of liberty. It can also be argued, however, that provided care or treatment does not deprive an informal incapacitated patient of liberty it can be lawful to treat them in a secure setting even if this amounts to some restriction of movement.

In response to the European Court judgement, The Mental Health Act Commission (2005) posit that patients who have capacity and agree to remain in a secure ward with various controls and restrictions are not likely to be deprived of their liberty provided they understand their informal status and right to terminate any agreement they may have made through discharging themselves from care. Clearly, each situation is different, even in a particular ward environment, because the patient's mental state and the associated risks continue to vary with time even in the latter stages of their admission.

It is worth reiterating that all care and treatment should be considered within a human rights framework in order not to unjustifiably deprive anyone of their liberty, thereby avoiding any legislative challenges in the future. Clearly, each patient has a different risk profile which means that a blanket operational policy covering such things as leave timing, places that can be visited, level of observation, use of mobile telephones etc. are not applicable to all informal patients. Jones (2005) considers the informal admission of patients at length in the light of the relevant European and domestic case law and suggests, among other things, that treatment in a secure ward, use of restraint in an emergency situation or placing of reasonable restrictions on visits by relatives or carers would not, by themselves, constitute deprivation of liberty. Crucially, any restrictions and controls placed on a patient must be proportional to the risks and not interfere with their rights more than necessary to achieve the intended objective. Consequently, it is essential that risk assessments are frequently reviewed and the controls and restrictions relaxed or tightened accordingly.

There are many other areas of care and treatment within the ward where relaxation of the usual rules could provide a less intrusive environment. For example, if an informal patient has been spending nights at home alone without problems a proportional response may be to increase their privacy in relation to Article 8 of The Human Rights Act 1998 by not observing them in their bedroom during the night (usual practice for inpatients in psychiatric wards). This issue remains open to debate as do many other similar issues associated with the possible infringement of human rights. The willingness to debate such issues constitutes good practice. Nonetheless, it is important that each patient's care and treatment is proportional to the assessed risk and is not covered by a 'blanket policy' applicable to all informal patients on a secure ward because, by definition, this would not be considered a proportional response to individual needs. It is suggested that in each case there should be a joint agreement regarding such things as providing information as to their whereabouts, informing staff of their expected time of return, adherence to reasonable communal living rules etc. Indeed, it is probable that the individually tailored agreement would, in many respects, be similar to that used in most shared residential type accommodation.

Unlike detained patients, there is no legal obligation to regularly remind informal patients of 
their legal status and the fact that they are free to leave hospital whenever they wish. Nonetheless, the Department of Health advice is to inform discharged patients in writing and verbally that their period of detention has ended (Jones, 2004). It is possible that some patients may subsequently remain in hospital for some considerable time and comply with requests made of them to remain in order to please staff or because they have few other viable options. Therefore, in order not to restrict the patient's liberty it is suggested that all informal patients are regularly reminded of their right to leave whenever they wish.

\section{References}

Jones, R. (2004) Mental Health Act Manual, London: Sweet and Maxwell.

Jones, R. (2005) Mental Health Act Manual: $1^{\text {st }}$ Supplement, London: Sweet and Maxwell.

Mental Health Act Commission (2005) Policy Briefing for Commissioners - Issue Eleven, Available from internet: http//: www.mhac.org.uk

Puri, B., Brown, R., McKee, H., Treaseden, I. (2005) Mental Health Law: A Practical Guide, London: Hodder Arnold. 
https://doi.org/10.1017/S1742646406000100 Published online by Cambridge University Press 